\title{
Studies on the Dehydroiodination of Cyclic $\beta$-Iodo-enol Ethers
}

\author{
Helena M. C. Ferraz", Myrian K. Sano, Fernanda I. Bombonato and Marta R. S. Nunes \\ Instituto de Química, Universidade de São Paulo, 05508-900 São Paulo - SP, Brazil
}

Este trabalho descreve a reação de desidroiodação, promovida por base, de uma série de $\beta$-iodoenol éteres cíclicos. Os produtos são tetraidrofuranos contendo duas ligações duplas exocíclicas, die tetraidrobenzofuranos e um derivado de diidropirano, todos obtidos em ótimos rendimentos.

This work describes the base-promoted dehydroiodination of differently substituted cyclic $\beta$-iodo-enol ethers. The products are tetrahydrofuran derivatives bearing two exocyclic double bonds, di- and tetrahydrobenzofurans and a dihydropyran derivative, which were obtained in very good yields.

Keywords: oxygen heterocycles, enol ethers, dihydroiodination

\section{Introduction}

The synthesis of oxygen containing heterocyclic rings continues to be an active research area, as attested by a number of recent papers dealing with this subject..$^{1-5}$ Cyclic ethers constitute the core of many natural products, including the important classes of polyether antibiotics ${ }^{6}$ and marine toxins. ${ }^{7}$ In particular, tetrahydrofuran moieties bearing an exocyclic double bond have been applied as useful precursors of Nonactic Acid, ${ }^{8}$ the monomeric structure of the antibiotics called Nonactins. ${ }^{9}$

In an earlier paper, ${ }^{10}$ we reported the results of a comparative study about the electrophilic cyclization of several alkenyl-substituted $\beta$-keto esters and $\beta$-diketones. Three different reagents, namely iodine, $p$-methoxyphenyltellurium trichloride and phenylselenenyl bromide, were employed as the electrophilic species for promoting the cyclofunctionalization reactions. In such a work, as well as in a previous communication, ${ }^{11}$ we reported the construction of a series of cyclic $\beta$-iodo-enol ethers containing an exocyclic double bond. We wish now to report the results of the dehydroiodination of these compounds.

\section{Results and Discussion}

The use of the sterically hindered base DBU $(1,8$ diazabicyclo[5.4.0]undec-7-ene) for promoting dehydroiodination reactions is well documented in the

* e-mail: hmferraz@iq.usp.br literature. In an earlier paper, ${ }^{12}$ we described the preparation of $\mathrm{N}$-substituted pyrrole and tetrahydroindole derivatives by DBU-promoted dehydroiodination of cyclic $\beta$-enamino-carbonyl compounds. Antonioletti et al. . $^{43,14}$ reported the dehydroiodination of several $\beta$-iododihydrofurans, followed by acid-catalyzed isomerization, to afford the corresponding furan derivatives.

Taking into account that the iodo-enol ethers 1-4 could lead to tetrahydrofurans bearing two exocyclic double bonds, which could be useful building blocks, we decided to submit then to treatment with DBU. The results are summarized in Table 1.

Table 1. Dehydroiodination of $\beta$-iodo-enol ethers 1-4 with DBU (2 equiv.) in toluene

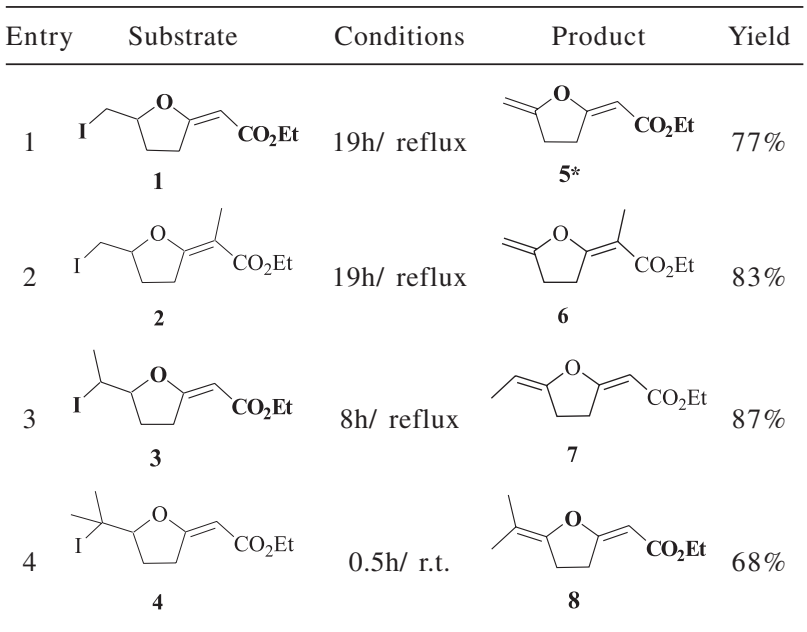

* Previously communicated in ref. 11. 
Under the employed reactional conditions, it did not occur any isomerization of the exocyclic double bonds. Such a behavior differs from that previously observed ${ }^{12}$ for the nitrogenated analogue of $\mathbf{1}$, which underwent a spontaneous aromatization, affording the corresponding pyrrole as the only isolated product. This is probably due to the greater aromatic character of pyrrole when compared to furan derivatives.

As it can be observed in Table 1, the reaction times ranged from 8 to $19 \mathrm{~h}$, in reflux of toluene, for the elimination of the secondary and primary iodides, respectively. The tertiary iodide underwent elimination very rapidly, at room temperature, which is in agreement with an $E_{2}$ process for all the substrates.

Accordingly, the bicyclic substrates 9-10, when submitted to the same reactional conditions, gave exclusively the products of the anti-elimination mechanism (Scheme 1). The stereostructure of $\mathbf{9}$ and 10, bearing the iodine in the axial position, belongs to what we suppose to be the most stable conformer, based upon the analysis of the ${ }^{13} \mathrm{C}$ and ${ }^{1} \mathrm{H}$ NMR spectra.

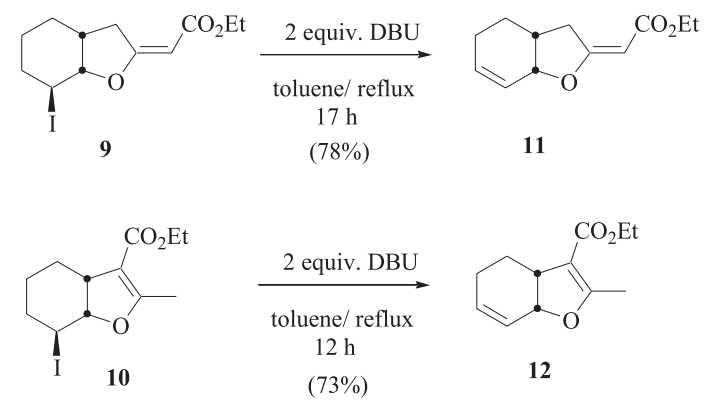

Scheme 1.

It must be mentioned that the dehydroiodination of the methyl ester analogous to $\mathbf{1 0}$ has already been described in the literature. ${ }^{4}$

Finally, we turned our attention to the six-membered ring derivatives $\mathbf{1 3}$ and $\mathbf{1 4}$. The former underwent the expected dehydroidination reaction, leading to the $\alpha$-methylidene dihydropyran $\mathbf{1 5}$ in very good yield. As already mentioned in our previous paper, ${ }^{10}$ treatment of the hemiketal 14 with DBU had furnished the bicyclic ketal 16, in a nonoptimized yield of $53 \%$. Running the reaction with excess of DBU led to the formation of a 2:1 mixture of $\mathbf{1 6}$ and the epoxide $\mathbf{1 7}$, in $80 \%$ overall yield (Scheme 2).

This later was identified in the NMR spectra of the mixture, by comparison with the data already published for the corresponding methyl ester. ${ }^{15}$

A probable sequence of events to explain the formation of $\mathbf{1 6}$ and $\mathbf{1 7}$ is depicted in Scheme 3. Through an internal

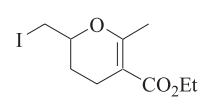

13

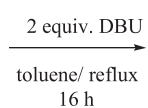

$16 \mathrm{~h}$
$(89 \%)$

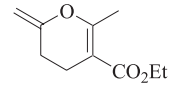

15

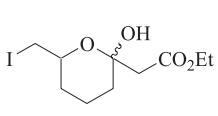

14

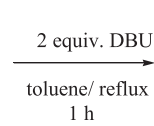

$1 \mathrm{~h}$
$(80 \%)$

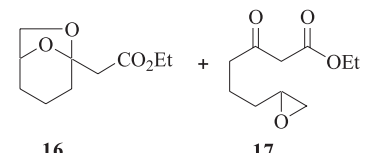

$(2: 1)$
17
Scheme 2.

$\mathrm{S}_{\mathrm{N}} 2$ process, only the isomer $14 \mathrm{a}$, which bears the hydroxyl and the iodomethyl groups in a cis-relationship, could lead to the bicyclic ketal 16. On the other hand, the hemiketal 14a can undergo a mutarotation process, leading to its trans-epimer $\mathbf{1 4 c}$, through the open keto form $\mathbf{1 4 b}$. Therefore, either the halohydrin $\mathbf{1 4 b}$ or the hemiketal $\mathbf{1 4 c}$ - which is unable to cyclize to $\mathbf{1 6}$ - could be the precursors of the epoxide 17.

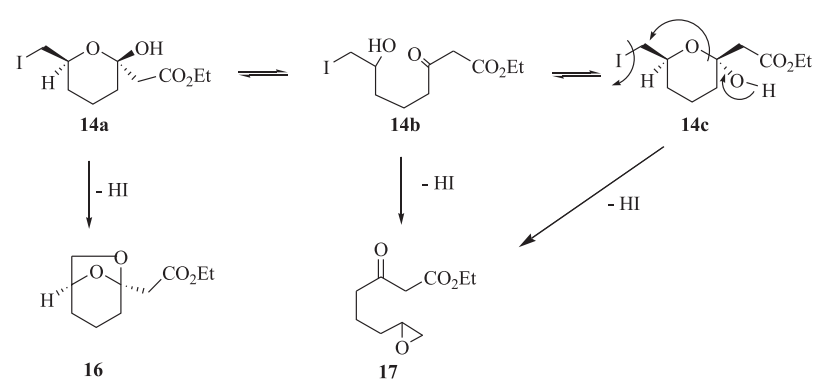

Scheme 3.

In summary, the results herein presented complement and expand our previous studies about the iodocyclofunctionalization of alkenyl-substituted- $\beta$-keto esters. In addition, these studies show the possibility of achieving useful functionalized oxygen-containing heterocycles in good yields.

\section{Experimental}

\section{General}

All solvents were dried by standard methods. ${ }^{1} \mathrm{H}$ and ${ }^{13} \mathrm{C}$ NMR spectra were recorded on Bruker AC-200, Bruker DPX-300 and Bruker DPX-500 MHz in $\mathrm{CDCl}_{3}$. Elemental analysis were carried out in a Perkin Elmer-2400/ CHN. IR spectra were recorded on a Perkin Elmer-FTIR. Melting points were carried out in an Electrothermal IA 9100 and are uncorrected. Column chromatography was performed using silica gel Acros 200-400 Mesh. TLC analyses were performed with silica gel plates Merck, using $p$-anisaldehyde solution, vanillin solution or iodine for 
visualization. The substrates $\mathbf{1 - 4}, \mathbf{9 - 1 0}$, and 13-14 were prepared as described in reference 10 .

\section{General procedure for dehydroiodination}

To a solution of the appropriate cyclic $\beta$-iodo-enol ether $(1 \mathrm{mmol})$ in toluene $(10 \mathrm{~mL})$ was added DBU $(2 \mathrm{mmol})$. The mixture was stirred at reflux for the time indicated in Table 1 or in Schemes 1-2 (monitored by CG), and then was filtered. The filtrate was diluted in $\mathrm{CH}_{2} \mathrm{Cl}_{2}$, washed with brine, dried over anhydrous $\mathrm{MgSO}_{4}$ and the solvent was evaporated. The crude product was purified by column chromatography.

2-(5-Methylene-dihydrofuran-2-ylidene)-propionic acid ethyl ester (6). Eluent: hexane/ ethyl acetate 9:1 (v/v); (83\%); white solid, mp 63.5-64.2 ${ }^{\circ} \mathrm{C}$; Calc. for $\mathrm{C}_{10} \mathrm{H}_{14} \mathrm{O}_{3}$ : C, 65.91; H, 7.74. Found: C, 66.07; H, 7.33; IR $v_{\max } / \mathrm{cm}^{-1}$ : 1685, 1635, 1127 (KBr); ${ }^{1} \mathrm{H}$ NMR $\left(\mathrm{CDCl}_{3}, 300 \mathrm{MHz}\right) \delta$ 1.29 (t, J 7.1 Hz, 3H), 1.87 (br s, 3H), 2.67-2.74 (m, 2H), 3.11-3.17 (m, 2H), 4.16-4.17 (m, 1H), 4.17 (q, J 7.1 Hz, $2 \mathrm{H}), 4.58-4.60(\mathrm{~m}, 1 \mathrm{H}) ;{ }^{13} \mathrm{C} \mathrm{NMR}\left(\mathrm{CDCl}_{3}, 75 \mathrm{MHz}\right) \delta 11.3$, 14.3, 26.5, 29.2, 59.7, 84.6, 100.1, 160.4, 167.4, 168,7.

(5-Ethylidene-dihydrofuran-2-ylidene)-acetic acid ethyl ester (7). Eluent: hexane/ ethyl acetate 9:1 (v/v); (87\%); colorless oil; Calc. for $\mathrm{C}_{10} \mathrm{H}_{14} \mathrm{O}_{3}$ : C, 65.91; H, 7.74. Found: C, 65.47; H, 7.34; ${ }^{1} \mathrm{H}$ NMR $\left(\mathrm{CDCl}_{3}, 300 \mathrm{MHz}\right) \delta$ $1.02(\mathrm{t}, J 7.1 \mathrm{~Hz}, 3 \mathrm{H}), 1.34(\mathrm{dt}, J 7.1$ and $1.5 \mathrm{~Hz}, 3 \mathrm{H}), 2.37-$ 2.44 (m, 2H), 2.91-2.97 (m, 2H), 3.88 (q, J 7.1 Hz, 2H), 4.79- $4.86(\mathrm{~m}, 1 \mathrm{H}), 5.13(\mathrm{t}, J 1.9 \mathrm{~Hz}, 1 \mathrm{H}) ;{ }^{13} \mathrm{C} \mathrm{NMR}\left(\mathrm{CDCl}_{3}\right.$, $75 \mathrm{MHz}) \delta 11.8,14.4,22.9,28.7,59.4,91.2,96.0,154.2$, 168.2, 174.0.

(5-Isopropylidene-dihydrofuran-2-ylidene)-acetic acid ethyl ester (8). Eluent: hexane/ ethyl acetate 9:1 (v/v); (68\%); colorless oil; Calc. for $\mathrm{C}_{11} \mathrm{H}_{16} \mathrm{O}_{3}$ : C, 67.32; H, 8.22. Found: C, 67.01; H, 8.01; IR $v_{\text {max }} / \mathrm{cm}^{-1}: 1705,1644,1118$ (film); ${ }^{1} \mathrm{H}$ NMR $\left(\mathrm{CDCl}_{3}, 300 \mathrm{MHz}\right) \delta 1.27(\mathrm{t}, J 6.6 \mathrm{~Hz}, 3 \mathrm{H})$, 1.61 (br s, 3H), 1.69-1.71 (m, 3H), 2.59-2.67 (m, 2H), 3.13$3.23(\mathrm{~m}, 2 \mathrm{H}), 4.19(\mathrm{q}, J 6.6 \mathrm{~Hz}, 2 \mathrm{H}), 5.39-5.41(\mathrm{~m}, 1 \mathrm{H}) ;{ }^{13} \mathrm{C}$ $\mathrm{NMR}\left(\mathrm{CDCl}_{3}, 75 \mathrm{MHz}\right) \delta 14.4,16.7,18.7,23.5,29.1,59.3$, $90.7,104.1,147.1,168.4,174.5$.

2-(3aßH, 7aßH-2,3,3a,4,5,7a-tetrahydrobenzofuran(7aH)-ylidene)-acetic acid ethyl ester (11). Eluent: hexane/ ethyl acetate 9:1 (v/v); (78\%); colorless oil; Calc. for $\mathrm{C}_{12} \mathrm{H}_{16} \mathrm{O}_{3}: \mathrm{C}, 69.21 ; \mathrm{H}, 7.74$. Found: C, 69.12; H, 7.65; IR $v_{\max } / \mathrm{cm}^{-1} 1700,1638,1114$ (film); ${ }^{1} \mathrm{H} \mathrm{NMR}\left(\mathrm{CDCl}_{3}\right.$, $300 \mathrm{MHz}) \delta 1.19(\mathrm{t}, J 7.1 \mathrm{~Hz}, 3 \mathrm{H}), 1.21-1.33(\mathrm{~m}, 1 \mathrm{H}), 1.61-$ 1.67 (m, 1H), 1.94-2.05 (m, 2H), 2.35-2.40 (m, 1H), 3.07 (d,
$J 5.5 \mathrm{~Hz}, 2 \mathrm{H}), 4.05$ (q, J7.1 Hz, 2H), 4.58 (br, 1H), 5.22 (br, $1 \mathrm{H}), 5.79-5.83(\mathrm{~m}, 1 \mathrm{H}), 6.01-6.06(\mathrm{~m}, 1 \mathrm{H}) ;{ }^{13} \mathrm{C} \mathrm{NMR}\left(\mathrm{CDCl}_{3}\right.$, $75 \mathrm{MHz}) \delta 14.4,23.0,23.2,34.2,36.6,59.0,78.1,89.9$, $123.2,133.8,168.6,175.4$.

3-(3aßH,4,5,7aßH-tetrahydro-2-methylbenzofuran)acetic acid ethyl ester (12). Eluent: hexane/ ethyl acetate 9:1 (v/v); (73\%); colorless oil; Calc. for $\mathrm{C}_{12} \mathrm{H}_{16} \mathrm{O}_{3}: \mathrm{C}, 69.21$. Found: C, 69.09; H, 7.55; H, 7.74; IR $v_{\max } / \mathrm{cm}^{-1}: 1696$, 1635, 1185 (film); ${ }^{1} \mathrm{H}$ NMR $\left(\mathrm{CDCl}_{3}, 300 \mathrm{MHz}\right) \delta 1.29(\mathrm{t}, J$ $7.1 \mathrm{~Hz}, 3 \mathrm{H}), 1.88-2.07$ (m, 4H), 2.19 (s, 3H), 2.97-3.06 (m, $1 \mathrm{H}), 4.13-4.35(\mathrm{~m}, 2 \mathrm{H}), 4.71-4.74(\mathrm{~m}, 1 \mathrm{H}), 5.91-5.95(\mathrm{~m}$, $1 \mathrm{H}), 6.16-6.21(\mathrm{~m}, 1 \mathrm{H}) ;{ }^{13} \mathrm{C} \mathrm{NMR}\left(\mathrm{CDCl}_{3}, 75 \mathrm{MHz}\right) \delta 14.3$, $14.4,23.1,24.8,40.0,59.2$, 78.0, 107.7, 123.1, 134.4, $166.3,168.4$.

3-(5,6-dihydro-2-methyl-6-methylene-4H-pyran)acetic acid ethyl ester (15). Eluent: hexane/ ethyl acetate 9:1 (v/v); (89\%); colorless oil; Calc. for $\mathrm{C}_{10} \mathrm{H}_{14} \mathrm{O}_{3}: \mathrm{C}, 65.91$; $\mathrm{H}, 7.74$. Found: C, 65.84; H, 7.49; ${ }^{1} \mathrm{H} \mathrm{NMR}\left(\mathrm{CDCl}_{3}\right.$, $500 \mathrm{MHz}) \delta 1.28(\mathrm{t}, J 7.1 \mathrm{~Hz}, 3 \mathrm{H}), 2.29(\mathrm{~s}, 3 \mathrm{H}), 2.41(\mathrm{~s}, 4 \mathrm{H})$, 4.15-4.53 (m, 2H), 4.17 (q, J 7.1 Hz, 2H); ${ }^{13} \mathrm{C} \mathrm{NMR}\left(\mathrm{CDCl}_{3}\right.$, $125 \mathrm{MHz}) \delta 14.4,19.5,21.5,25.4,59.9,91.0,103.0,155.4$, $161.8,167.8$.

\section{Acknowledgments}

The authors are indebted to FAPESP, CNPq and CAPES for financial support. The authors wish to thank Patricia R. Marques for performing initial experiments.

\section{References}

1. Nakamura, I; Yamamoto, Y.; Chem. Rev. 2004, 104, 2127.

2. Tiecco, M.; Testaferri, L.; Bagnoli, L.; Purgatorio, V.; Temperini, A.; Marini, F.; Santi, C.; Tetrahedron: Asymmetry 2004, 15, 405.

3. Stefani, H. A.; Silva, D. O.; Costa, I. M.; Petragnani, N.; J. Heterocycl. Chem. 2003, 40, 163.

4. Antonioletti, R.; Malancona, S.; Cattaruzza, F.; Bovicelli, P.; Tetrahedron 2003, 59, 1673.

5. Lee, Y. R.; Suk, J. Y.; Tetrahedron 2002, 58, 2359.

6. Boivin, T. L. B.; Tetrahedron 1987, 43, 3309.

7. Alvarez, E.; Candenas, M.-L.; Pérez, R.; Ravelo, J. L.; Martín, J. D.; Chem Rev. 1995, 95, 1953.

8. Beck, G.; Henseleit, E.; Chem. Ber. 1971, 104, 21.

9. For a review, see: Ferraz, H. M. C.; Payret-Arrúa, M. E.; Quim. Nova 1998, 21, 597.

10. Ferraz, H. M. C.; Sano, M. K.; Nunes, M. R. S.; Bianco, G. G.; J. Org. Chem. 2002, 67, 4122. 
11. Ferraz, H. M. C.; Sano, M. K.; Scalfo, A. C.; Synlett 1999, 567.

12. Ferraz, H. M. C.; Pereira, F. L. C.; Leite, F. S.; Nunes, M. R. S.; Payret-Arrúa, M. E.; Tetrahedron 1999, 55, 10915.

13. Antonioletti, R.; Bonadies, F.; Scettri, A.; Tetrahedron Lett. 1988, 29, 4987 .
14. Antonioletti, R.; Cecchini, C.; Ciani, B.; Magnanti, S.; Tetrahedron Lett. 1995, 36, 9019.

15. Sum, P.-E.; Weiler, L.; Can. J. Chem. 1979, 57, 1475.

Received: January 17, 2005 Published on the web: July 07, 2005

FAPESP helped in meeting the publication costs of this article. 